12. Adzizes, I. (2006). Idealnyi kerivnuk: chomu vy ne mozhete staty nym i scho robyty $\mathrm{z}$ cogo pryvodu
[Perfect head: why you can not be him and what to do about it]. Kyiv-Mohyla Academy, 266.

Дата надходження рукопису 27.01.2015

Драч Ірина Іванівна, доктор педагогічних наук, доцент, заступник директора, Інститут менеджменту та психології, ДВНЗ «Університет менеджменту освіти» НАПН України, вул. Артема, 52-А, м. Київ, Україна, 04053

E-mail: drach_i@ukr.net

\author{
УДК 37.013.75 \\ DOI: 10.15587/2313-8416.2015.37399
}

\title{
ИЗУЧЕНИЕ ТЕМЫ «АЛГОРИТМЫ» В НАЧАЛЬНОЙ ШКОЛЕ С ПОМОЩЬЮ ПРИОБРЕТЁННЫХ ЗНАНИЙ ПО МАТЕМАТИКЕ
}

\author{
(C) О. А. Рыбалко
}

Статья посвящена вопросу разработки и использования электронных образовательных ресурсов по математике и информатике для начальной школь в программе Adobe Flash на примере электронного учебного пособия "Алгоритмы и математика», которое можно использовать как на уроках математики, так и на уроках информатики во время изучения темы «Алгоритмы»»

Ключевые слова: Adobe Flash, электронное учебное пособие, алгоритмы, вычисления, игровые методы обучения

The article is devoted to the development and use of electronic educational mathematical and computing resources for primary schools in the program Adobe Flash on example of electronic textbook "Algorithms and mathematics". This textbook can be used on the lessons of mathematics and informatics while exploring the theme "Algorithms"

Keywords: Adobe Flash, electronic textbook, algorithms, calculations, game teaching methods

\section{1. Введение}

Сегодня компьютерные технологии можно считать тем новым способом передачи знаний, который отвечает более качественному содержанию обучения и развития ребенка, позволяет ему с интересом учиться, находить источники информации, воспитывает самостоятельность и ответственность при получении новых знаний, развивает дисциплину интеллектуальной деятельности.

Современный уровень развития науки и техники, компьютеризация общества, инновационные технологии предъявляют новые требования к умениям и навыкам учеников. Чтобы в будущем младшие школьники умели не только получать знания, но и решать разнообразные практические и теоретические задания, смогли бы самостоятельно добывать нужные умения и навыки, адекватно и умело действовать, решая разные учебные проблемы, ученик должен научиться думать. Если мы хотим вырастить такого человека, то нужно стремиться формировать у школьников общие методы мушления, общие способы подхода к любому заданию и проблеме. Алгоритм и является одним из видов общих методов деятельности вообще, а не только умственной деятельности.

\section{2. Постановка проблемы}

Понятие алгоритма проникает во все отрасли современной математики от начальной к высшей.
Для математики алгоритмы - одно из фундаментальных понятий основ математики. Обучение математике на любом уровне обязательно включает обучение алгоритмам. Умение форму-лировать и применять алгоритмы важно не только для развития математического мышления и математических умений, оно подразумевает также и умение формулировать правила и выполнять их. Алгоритмизация обучения рассматривается в современном обучении в двух значениях: обучение учеников алгоритмам, а также построение и использование алгоритмов в обучении.

\section{3. Литературный обзор}

В последние годы вопрос о необходимости специальной работы учителя начальных классов над развитием логической и алгоритмической составляющей мышления ребенка приобретает особенную остроту по следующим причинам: во - первых, появились новые учебники для начальных классов, требующие от ученика активной мыслительной деятельности для усвоения их содержания; во вторых, как в начальном, так и в среднем звене школы активно внедряются факультативные курсы логики и курс «Инфор-матика», для изучения которого необходимо усилить логическую и алгоритмическую подготовку учеников младших классов [1]. 
Поиск новых подходов к развитию личности, формирование ее современного мировосприятия побуждает педагогов к использованию проблемного, деятельностного и компетентностного подходов [2].

Знакомство с алгоритмами - традиционный раздел практически любого курса информатики, поскольку способность выполнять и разрабатывать алгоритмы занимает одно из центральных мест при обработке информации и решении задач. Школьники учатся детально описывать алгоритм выполнения задания, а это в свою очередь помогает приобре-тению навыков разбивать свою деятельность на отдельные четкие простые действия. Зачем это нужно? Человеку, который не владеет алгоритм-мическим мышлением, тяжело дать четкую и понятную инструкцию (алгоритм), разбитую на отдельные простые команды. Ведь именно такая инструкция легче воспринимается и запоминается. Необходимая упорядоченность и четкость в зложении информации. Алгоритмирование определяет строгую логическую последовательность, непрерывность мыслительной деятельности, посте-пенно подводящей ученика к самостоятельному «открытию» истины и позволяющей избежать логических провалов [3].

Формирование алгоритмической культуры учеников начальной школы заключается в усвоении на интуитивно-практическом уровне понятийного аппарата и соответствующих способов поэтапной деятельности. На этом уровне ведущим элементом обучения является познавательная деятельность учеников, в процессе которой усваиваются общие умения и навыки, нужные для работы в информационной среде, формируются основные алгоритмические представления (деятельностный аспект алгоритмической культуры) [4].

Составление алгоритмических распоряжений - сложное задание, поэтому начальный курс марема-тики не ставит целью его решение. Но определенную подготовку к достижению этой цели он может и должен взять на себя, содействуя тем самым развитию логического и алгоритмического мышления школьников. Человек выступает прежде всего как деятель. В деятельность всегда включаются умения и навыки. Потому-то учитель должен использовать все возможное, чтобы обеспечить высокую алгоритмическую подготовку ученика. Алгоритмический подход к решению заданий содействует развитию у детей умения мыслить [5].

\section{4. Изучение темы «Алгоритмы» с помощью} электронного учебного пособия «Алгоритмы и математика»

C помощью приобретенных знаний по математике можно выучить тему «Алгоритмы». С этой целью и было создано электронное пособие «Алгоритмы и математика» преподавателем колледжа в сотрудничестве со студентами. Используя данное пособие, можно выучить темы:
«Алгоритмы и исполнители», «Свойства алгоритммов», «Способы записи алгоритмов», «Алгоритм составления магических квадратов», «Запись алгоритмов языком стрелок», «Виды алгоритмов». Следует отметить, что материал пособия тесно связан с начальным материалом по математики, который изучается в 3 классе.

Электронное пособие «Алгоритмы и математика» сделано в программе Adobe Flash, которая является мощным средством для создания электронных образовательных ресурсов. Главный козырь Flash - собсвенный язык программирования Action Script. C помощью этого языка можно руководить любым элементом программного продукта и изменять его свойства [6]. В результате применения языка программирования Action Script учитель имеет намного больше возможностей для создания интересного и качественного электронного ресурс. Рассмотрим электронное учебное пособие «Алгоритмы и математика», которое создано в программе Adobe Flash CS 3. Электронное учебное пособие «Алгоритмы и математика» ориентировано на учителей, студентов высших педагогических учебных заведений и учеников начальных классов. Материал пособия подобран в соответствии с учебной программой по математики для 1-4 классов общеобразовательных учебных заведений. Учитель может использовать его как на уроках математики, так и на уроках информатики в начальных классах во время изучения темы «Алгоритмы» $[5,6]$.

Электронное учебное пособие выполнено в формате, который допускает систему навигации, дающую возможность пользователю свободно перемещаться разделами пособия, работать в разных режимах. Данное электронное пособие служит дидактическим средством, которое можно использовать на разных этапах обучения с целью усвоения новых знаний, закрепления и совершенствования знаний, умений и навыков, а также проверки и коррекций учебных достижений учеников. Учитель может применять пособие во время проведения уроков, а ученики имеют дополнительную возможность учиться в удобное для себя время, в индивидуальном темпе. Это способ-ствует интенсификации труда как учителя, так и ученика. Материал пособия является доступным для восприятия учениками начальных классов. Электронное пособие можно установить на любую модель компьютера: обычный стационарный персональный компьютер, ноутбук, нетбук или планшет.

Проиллюстрируем некоторые возможности электронного пособия «Алгоритмы и марематика».

На титульной электронной странице (рис. 1) расположены: инструкция, сведения об авторах и использованных ресурсах. Нажимая на кнопку с красной стрелкой, расположенную внизу электронной страницы, ученик может начать работу с данным электронным пособием (рис. 1,2$)$. 


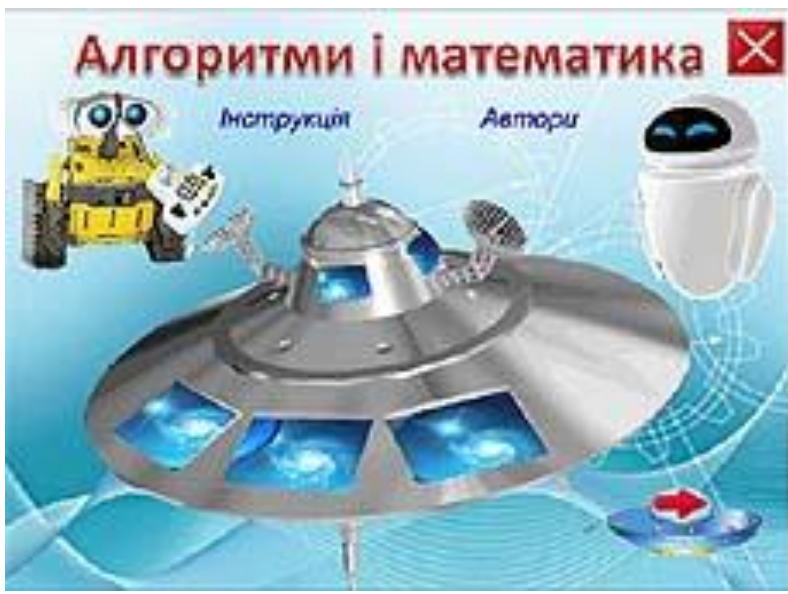

Рис. 1. Титульная электронная страница пособия

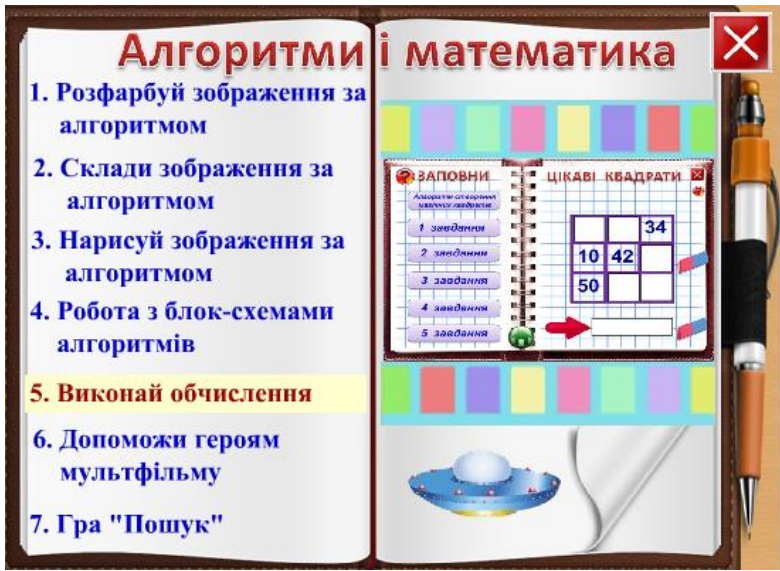

Рис. 2. Список игровых заданий

К каждой игре даётся инструкция, которая имеет название «Алгоритм исполнения». Таким образом, незаметно для себя ученик начальных классов становится исполнителем (рис. 3).

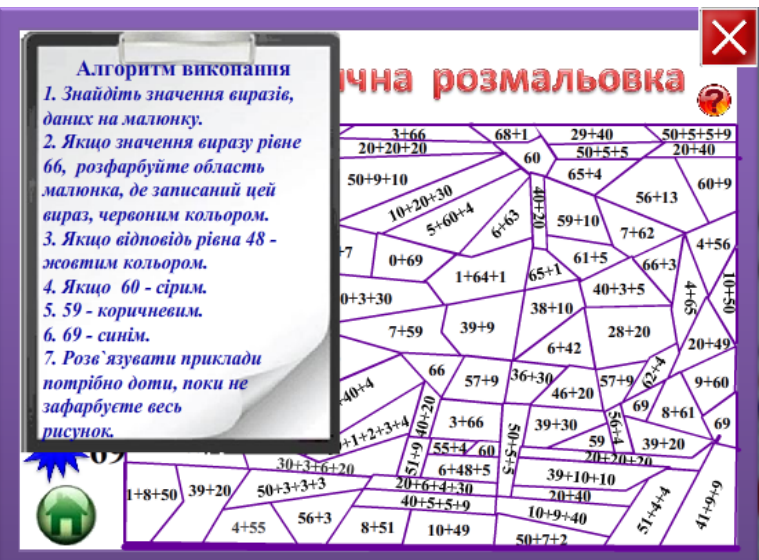

Рис. 3. Алгоритм исполнения выбранного задания

Задания для младших школьников стремились сделать интересными и захватывающими. Например, игра «Математические раскраски» позволяет ученикам повторить случаи сложения и вычитания в пределах сотни. Для этого нужно выбрать соответствующую часть изображения и решить записанное задание. Нужно подвести курсор к краске, расположенной возле правильного ответа, после чего подвести курсор к выбранной детали, которая приобретёт такой же цвет. Так нужно работать, пока не будет раскрашено полностью изображение (рис. 4).

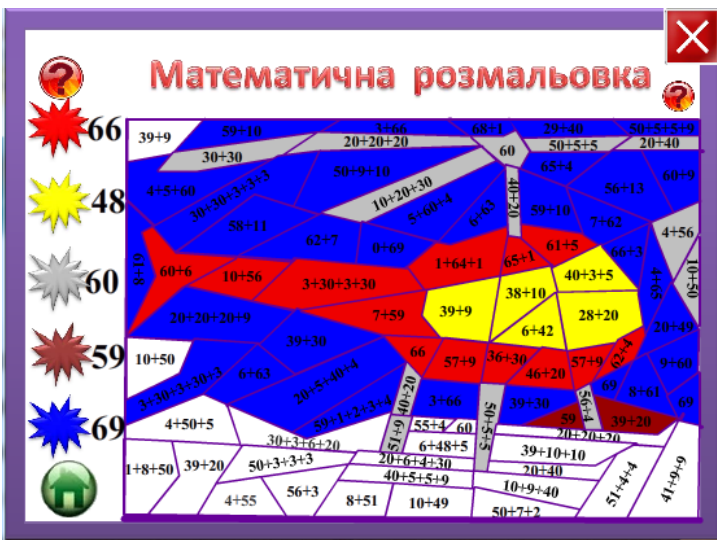

Рис. 4. Игра «Математическая раскраска»

Умение учеников оформить свои мысли и весь ход решения задания в виде таблицы или же блоксхемы существенно дисциплинирует мышление учеников, стаёт необходимым практическим качеством, способствует более быстрому и осмысленному овладению алгоритмическим языком в будущем. Ученики могут учиться изображать алгоритмы в виде блок-схем. Они изучают виды блок-схем и учатся их составлять, пользуясь образцом слева (рис. 5).

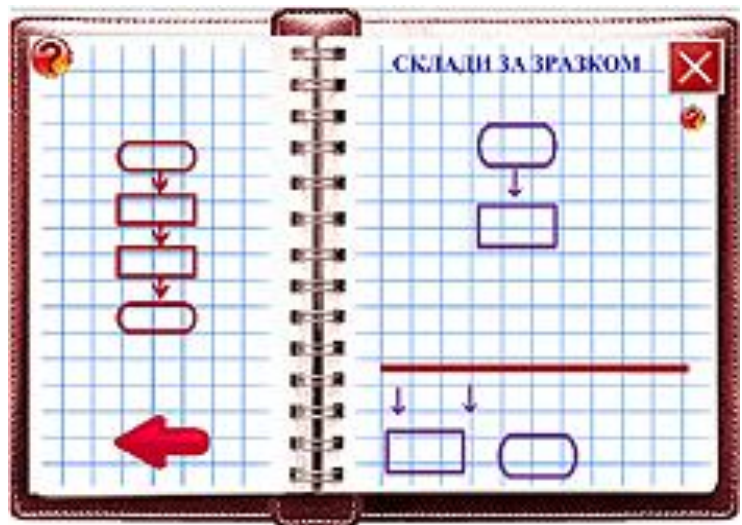

Рис. 5. Составление блок-схем по образцу

После этого ученики имеют возможность выполнять математические действия, используя блок-схемы алгоритмов (рис. 6).

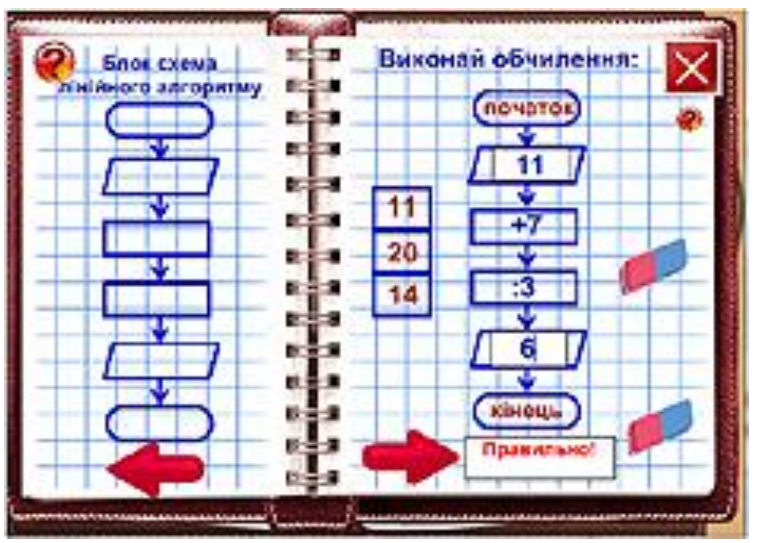

Рис. 6. Выполнение математических действий с помощью блок-схем 
Младшие школьники научились вычислять, подставляя числа, размещённые в клеточках данных блок-схем. На левой стороне блокнота размещённый образец, а на правой - ученик должен выполнить задание. С помощью стрелки красного цвета можно проверить, правильно ли сделано задание. А с помощью резинки можно очистить поля, если ответ неправильный и выполнять задание сначала [7].

Математическое мышление со свойственным ему чёткостью, системой, последовательностью и логичностью является примером правильно организованного мышления. Владение марема-тическим и алгоритмическим языком, понимание точного значения утверждений и связей между логическими конструкциями в заданиях, имеют существенное влияние на языковое развитие особенности младшего школьника и тем самым делают существенный взнос для формирования и развития мышления в целом.

На рис. 7, 8 изображены наиболее интересные задания. Вместе с любимыми героями третьеклас сники выполняют вычисления, усваивая одновременно, как нужно работать с блок-схемами алгоритмов.

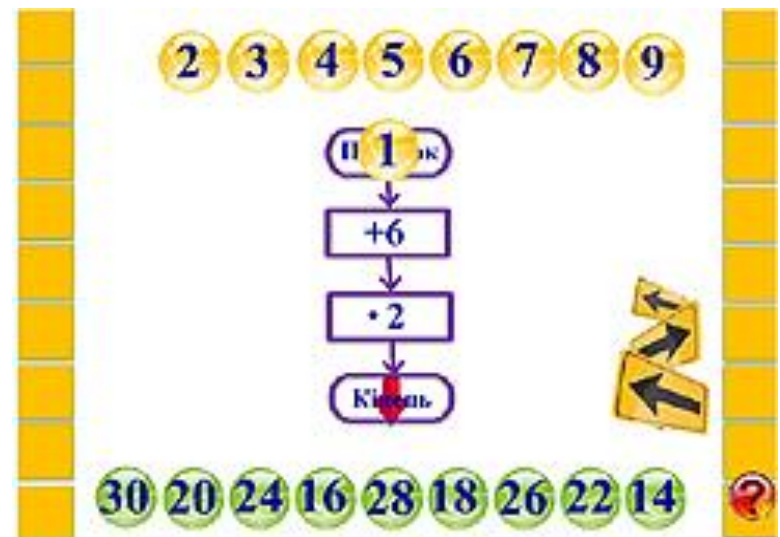

Рис. 7. Выполнение математических заданий с помощью линейных алгоритмов

Выбрав число 1 (рис. 7), ученик может наблюдать с помощью красной стрелки, как работает «вычислительная машина». После этого ученик может выбрать любое число, размещённое в верхней строке. Младший школьник выполняет вычисления, подставляя выбранное число в соответствующую блок-схему. А ответ нужно искать в нижней строке данной электронной страницы.
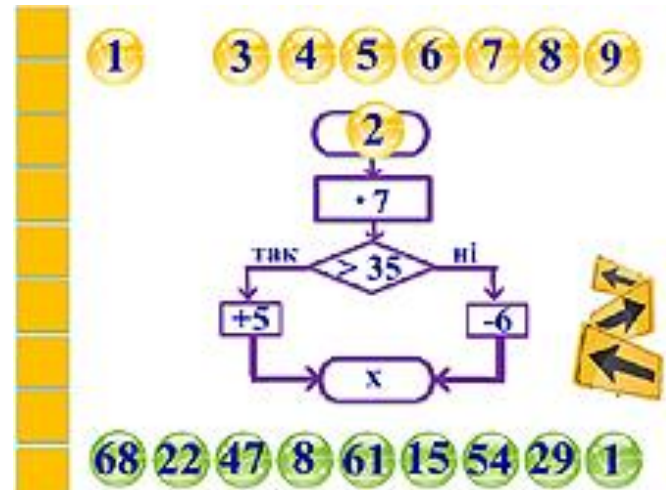

Рис. 8. Выполнение математических заданий с помощью разветвляющихся алгоритмов
Если задание выполнено правильно, то появляется ответ «Правильно» (рис. 9), а если неправильно, то ответ «Неправильно».

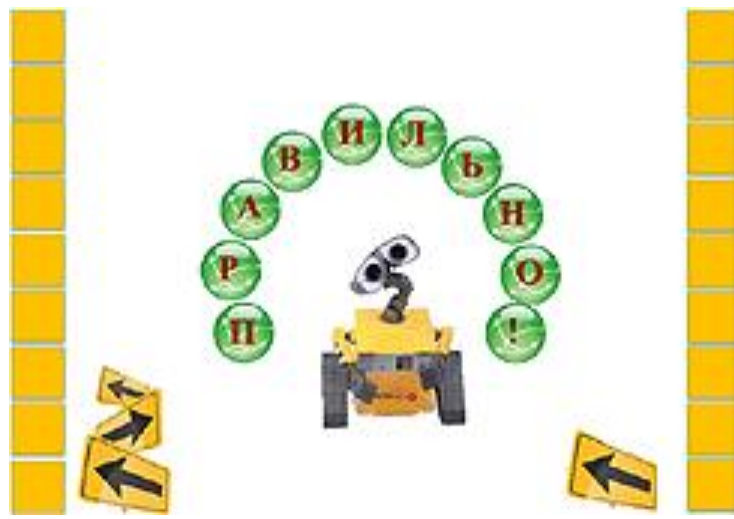

Рис. 9. Реакция героев на правильный ответ

Как итог, было проведено тестирование (рис. 10). Ведь контроль знаний и умений учеников является важным звеном процесса обучения школьников. От того, как он организован и на что ориентирован, существенно зависит эффективность всей учебной работы [8].

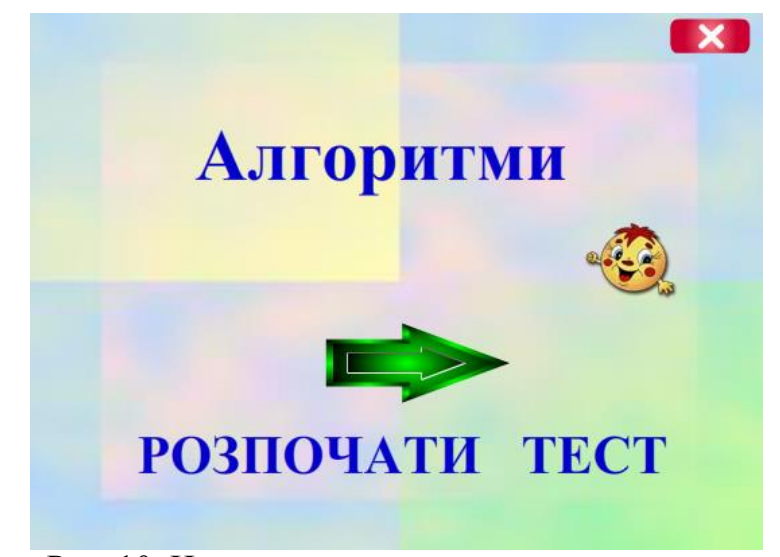

Рис. 10. Начальная страница тестового задания

Очень важно сегодня процесс тестирования сделать таким, который не вызывает страха, а стимулирует последующее самоусовершенствование младшего школьника (рис. 11, 12).

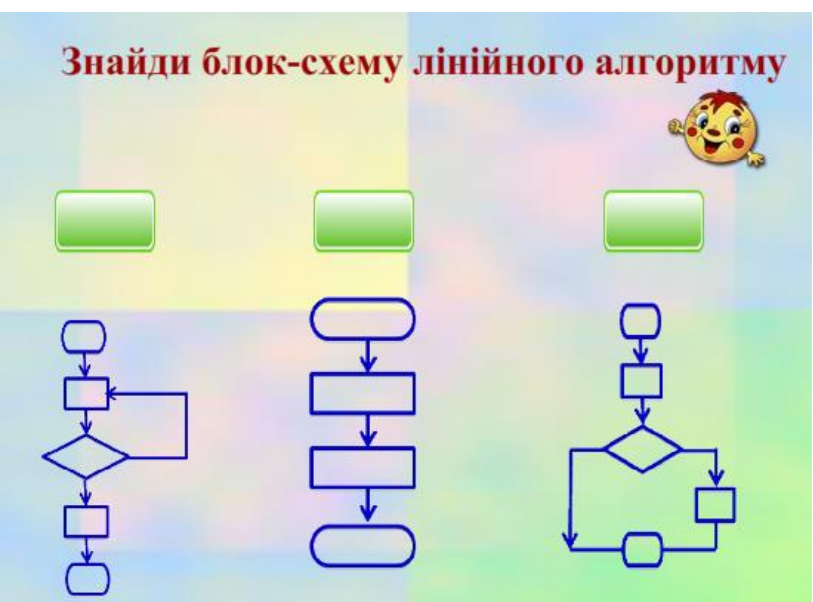

Рис. 11. Одно из заданий, предложенных ученикам 
Следует отметить, что ученики с большим удовольствием выполняют тестовые задания. И очень радуются, когда видят ожидаемый результат (рис. 12).

Стараются работать до тех пор, пока не увидят хорошую отметку.

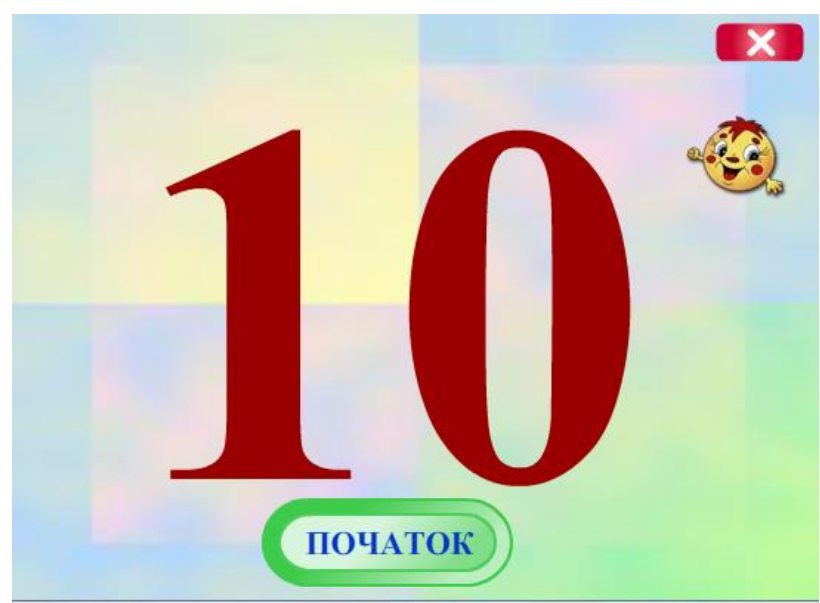

Рис. 12. Отображение результатов тестирования

\section{5. Апробация результатов исследований}

Студенты Прилукского гуманитарнопедагогического колледжа им. И. Я. Франка проводили занятия кружка «Алгоритмы и математика» в одной из школ города. Они имели возможность проанализировать, какие задания больше нравятся ученикам, а какие нравятся меньше. Например, младшие школьники любят раскраски. А задания, где нужно заполнять магические квадраты, ученики не очень полюбили. Нужно отметить, что на уроках математики без компьютерного сопровождения ученики начальных классов заполняют магические квадраты с удовольствием [9]. А от компьютера они ожидают более интересных и необычных заданий. Следовательно, моделируя игровые задания для занятий с компьютерным сопровождением, нужно подбирать интересные и разнообразные дидактические игры, в которые ученики не играют на уроках без использования компьютера.

\section{6. Выводы}

Проработав с третьеклассниками данный материал, мы сделали выводы, что учитель не имеет морального права начинать курс без качественного программного обеспечения для учеников, ведь младшие школьники так ожидают общения с компьютером. Кроме того, материала, рас положенному в пособии, оказалось маловато. Нужно, чтобы у всех учеников была рабочая тетрадь. Каждый раз мы готовили задание для учеников на отдельных листах. Но в будущем решили сделать рабочие тетради, где был бы расположен материал, который необходимо запомнить ученикам и задания, которые они будут выполнять на уроках.

Применение электронного пособия во внеурочное время позволит сделать более разнообразными формы и средства обучения, повзсить творческую активность учеников, активизировать самостоятельную работу младших школьников. Следовательно, приме- нение совре-менных технических средств позволяет не только улучшить само качество воспитания и образования, но и повысить познавательный интерес детей. Применение ИКТ, безусловно, улучшает учебный процесс, развивает творческие способности и вызывает живую заинтересованность учеников. Преимущества ИКТ открываются с самого начала, и в меру их использования дают толчок к развитию самого педагога, позволяя оставаться ему всегда современным, антересным и нужным для детей.

\section{Литература}

1. Белошистая, А. В. Развитие логического и алгоритмического мышления младшего школьника [Текст] / А. В. Белошистая, В. В. Левитас // Начальная школа до и после. - 2006. - № 9. - С. 15 -23.

2. Пушкарёва, Т. А. Электронный контент: особенности применения и новые возможности познания мира $[$ Текст] / Т. А. Пушкарёва // Компьютер в школе и семье. - 2011. - № 4. - С.7-10.

3. Гажук, Н. И. Формирование элементов логичес-кой и алгоритмической грамотности [Текст] / Н. И. Гажук // Начальная школа плюс до и после. 2011. - № 7. - С. 30-32.

4. Мельник, Ю. С. Подготовка учителя к формированию алгоритмической культуры младших школьников [Текст] / Ю. С. Мельник // Психолого-педагогические проблемы сельской школы. - 2009. - № 31. - С. 52-61.

5. Рыбалко, О. А. Алгоритмы и математика в начальной школе [Текст] / О. А. Рыбалко // Компьютер в школе и семье. - 2014. - № 3. - С. 26-29.

6. Мук, К. Action Script 3.0 для Flash [Текст] / К. Мук. - П: Питер, 2009. - 987 с.

7. Рыбалко, О. А. Создание заданий с использованием текстовых полей в программе Adobe Flash CS3 Professinal [Текст] / О. А. Рибалко // Компьютер в школе и семье. - 2011. - № 2. - С. 25-29.

8. Рыбалко, О. А. Создание тестов для младших школьников в программе Macromedia Flash Professional 8 [Текст] / О. А. Рибалко // Компьютер в школе и семье. 2008. - № 4. - С.17-19.

9. Планкина, Д. Ю. Использование магических квадратов для развития умения рассуждать [Текст] / Д. Ю. Планкина // Начальная школа. - 2013. - № 11. С. $66-70$.

\section{References}

1. Beloshistaya, A. V., Levites, V. V. (2006). The development of logical and algorithmic thinking junior schoolboy [Razvivie logicheskogo i algoritmicheskogo mishlenia mldshego shkolnika]. Primary school before and after, 9, 15-23

2. Pushkaryova, T. A. (2011). Electronic content: application features and new opportunities knowledge of the world [Elektronnyy content: osobennosti primeneniya i novye vozmozhnosti poznaniya mira]. Computer in school and family, 4, 7-10.

3. Gazhuk, N. I. (2011). Formation of elements of logic and algorithmic literacy [Formirovanie elementov logucheskoy I algoritmicheskoy gramotnosti]. Primary school before and after, 7, 30-32.

4. Melnik, Yu. S. (2009). Prepaning theachers to the formation of algorithmic culture of younger schoolboys [Podgotovka uchitelya $\mathrm{k}$ formirovaniyu algoritmicheskoy kultury mladshih shkolnikov]. Psychological and pedagogical problems of rural schools, 31 (56), 52-61.

5. Rybalko, O. A. (2014). Algorithms and mathematics in primary school [Algoritmy $\mathrm{i}$ matematika $\mathrm{v}$ nachalnoy shkole]. Computer in school and family, 3, 25-29. 

Piter, 987.

6. Moock, K. (2009). Action Script 3.0 for Flash.

7. Rybalko, O. A. (2011). Create a task using the text fields in the program Adobe Flash CS3 Professinal [Sozdanie zadaniy s ispolzovaniem tekstovyh poley v programme Adobe Flash CS3 Professinal]. Computer in school and family, 2, 25-29.
8. Rybalko, O. A. (2008). Creation tests for younger

students in the program Macromedia Flash Professional 8 [Sozdanie testov dlya mladshih shkolnikov $\mathrm{v}$ programme Macromedia Flash Professional 8]. Computer in school and family, 4, 17-19.

9. Plankina, D. Yu. (2013). The use of magic squares for the development of the ability to reason [Ispolzovanie magicheskih kvadratov dly razvitiya umeniya rassuzhdat]. Primary school, 11, 66-70.

Рекомендовано до публікаиії д-р пед. наук Бурда М. I. Дата надходження рукопису 28.01.2015

Рыбалко Ольга Алексеевна, преподаватель, Прилукский гуманитарно-педагогический коллледж им. И. Я.Франка, ул. Порбеды, 170, г. Прилуки, Черниговской обл., Украина, 17500

Email: RybalkoOlga2009@rambler.ru

\author{
УДК 378.147.091.33-021.464 \\ DOI: 10.15587/2313-8416.2015.37480
}

\title{
САМОСТОЯТЕЛЬНАЯ РАБОТА СТУДЕНТОВ КАК ПЕДАГОГИЧЕСКАЯ ПРОБЛЕМА
}

\author{
(C) Е. А. Рощупкина
}

Цель данной статьи - описать самостоятельную работу студентов как педагогическую проблему, а именно: определить место самостоятельной работы в системе дидактических понятий, раскрыть сущность самостоятельной работь студентов в педагогике, психологии и методике преподавания иностранных языков, в том числе русского языка как иностранного, проанализировать аспекты самостоятельной работьл

Ключевые слова: самостоятельная работа, самостоятельная деятельность, автономия, сущность, аспект, иностранные студенты, довузовский этап

The purpose of this article - to describe self-independent work of students as a pedagogical problem, namely: to define a place of independent work in system of didactic concepts, to explain essence of self-independent work of students in pedagogics, psychology and a methodology of teaching the foreign languages, including Russian as foreign, to analyze aspects of self-independent work

Keywords: self-independent work, self-independent activity, autonomy, essence, aspect, foreign students, preuniversity stage

\section{1. Введение}

На этапе интеграции образования в единое европейское научное пространство возрастают требования к уровню знаний студентов. Одним из важных условий обеспечения высокого качества подготовки будущих специалистов, готовых к постоянному профессиональному росту, способных учиться на протяжении всей жизни, является усиление роли самостоятельной работы (СР).

\section{2. Постановка проблемы}

Увеличение объема самостоятельной работы, доля которой при кредитно-модульном обучении составляет более $40 \%$, повышение ее значения влечет за собой реорганизацию учебного процесса в вузе, создание условий для развития и самореализации каждого студента и прежде всего для формирования у него умения учиться самостоятельно. В связи с этим назрела необходимость изменения содержания $\mathrm{CP}$, дальнейшего изучения ее различных аспектов и подходов к данной проблеме, в том числе при обучении иностранных студентов на довузовском этапе - подготовительном факультете.

\section{3. Литературный обзор}

В научной литературе рассматриваются различные аспекты самостоятельной работы: общепедагогические подходы к раскрытию сущности СР студентов (М. Гарунов, В. Козаков, А. Молибог, П. Пидкасистый и др.), ее планирование и организация (Б. Есипов, И. Лернер и др.), проблемы управления и контроля (И. Андреева, К. Есипович, Л. Жарова, А. Лында и др.), значение самообразования и самоподготовки к профессио-нальной деятельности (А. Громцева, Ю. Кулюткин, Г. Сухобская и др.), механизмы развития самостоятельности и активности личности в разных видах деятельности (П. Гальперин, В. Давыдов, Е. Кабанова-Миллер и др.) и т. д. [1-12]. Отдельные частнометодические аспекты СР иностранных студентов изучают О. Отменитова, Л. Прядина, Л. Сеник и др. 